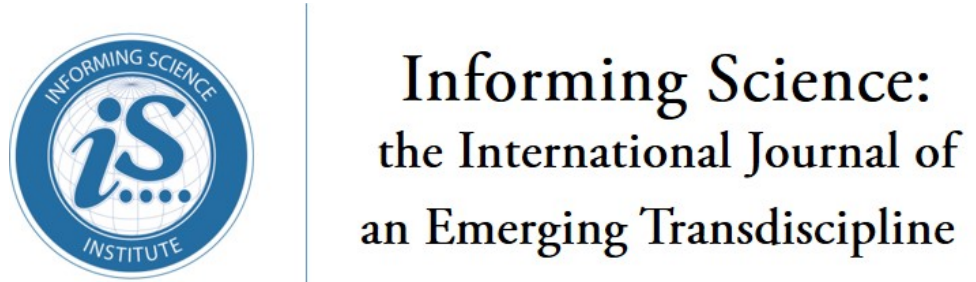

An Official Publication

of the Informing Science Institute

InformingScience.org

Inform.nu

Volume 20, 2017

\title{
INFORMATION RE-SHARING ON SOCIAL NETWORK SITES IN THE AGE OF FAKE NEWS
}

$\begin{array}{lll}\text { Mehrdad Koohikamali* } & \begin{array}{l}\text { University of Redlands, } \\ \text { Redlands, CA, USA }\end{array} & \text { Mehrdad_Koohikamali@redlands.edu } \\ \text { Anna Sidorova } & \begin{array}{l}\text { University of North Texas, } \\ \text { Denton, TX }\end{array} & \text { Anna.Sidorova@unt.edu }\end{array}$

ABSTRACT

Aim/Purpose In the light of the recent attention to the role of social media in the dissemination of fake news, it is important to understand the relationship between the characteristics of the social media content and re-sharing behavior. This study seeks to examine individual level antecedents of information re-sharing behavior including individual beliefs about the quality of information available on social network sites (SNSs), attitude towards SNS use and risk perceptions and attitudes.

Methodology Testing the research model by data collected through surveys that were administered to test the research model. Data was collected from undergraduate students in a public university in the US.

Contribution This study contributes to theory in Information Systems by addressing the issue of information quality in the context of information re-sharing on social media.

This study has important practical implications for SNS users and providers alike. Ensuring that information available on SNS is of high quality is critical to maintaining a healthy user base.

Findings Results indicate that attitude toward using SNSs and intention to re-share information on SNSs is influenced by perceived information quality (enjoyment, relevance, and reliability). Also, risk-taking propensity and enjoyment influence the intention to re-share information on SNSs in a positive direction.

Future Research In the dynamic context of SNSs, the role played by quality of information is changing. Understanding changes in quality of information by conducting longitudinal studies and experiments and including the role of habits is necessary.

Keywords social network, fake news, information quality, risk taking propensity, re-sharing

Accepting Editor Kay Fielden | Received: May 30, 2017| Revised: August 23, August 31, 2017 | Accepted: October 3, 2017.

Cite as: Koohikamali, M., \& Sidorova, A. (2017). Information re-sharing on social network sites in the age of fake news. Informing Science: the International Journal of an Emerging Transdiscipline, 20, 215-235. Retrieved from http://www.informingscience.org/Publications/3871

(CC BY-NC 4.0) This article is licensed to you under a Creative Commons Attribution-NonCommercial 4.0 International License. When you copy and redistribute this paper in full or in part, you need to provide proper attribution to it to ensure that others can later locate this work (and to ensure that others do not accuse you of plagiarism). You may (and we encourage you to) adapt, remix, transform, and build upon the material for any non-commercial purposes. This license does not permit you to use this material for commercial purposes. 


\section{INTRODUCTION}

In 2013 Facebook announced exceeding 1 billion active users worldwide, and reaching 1 billion active mobile users in 2014 (Wagner, 2014). As of the first quarter of 2016, Twitter boasted over 310 million monthly active users, and over 500 million tweets sent per day (https://about.twitter.com/company ). Communication, networking, and information sharing are among the key reasons for using social media (Ahn, Han, Kwak, Moon, \& Jeong, 2007), and, as a result, social media is emerging as one of the key platforms for information dissemination (Xiang \& Gretzel, 2010). Information sharing on SNS typically involves one of two forms: self-disclosure, the sharing of personal information by a user, and re-sharing, whereby users share content that is posted by other SNS users or third parties. Re-sharing behavior, which may be referred to as retweeting, sharing, re-vining, or re-blogging, is one of the major mechanisms of online information dissemination (Suh, Hong, Pirolli, \& Chi, 2010) and, as such, represents an important category of informing (Cohen, 2009). SNSs such as Twitter, YouTube, and Facebook are used for rapid information dissemination (Mislove, Marcon, Gummadi, Druschel, \& Bhattacharjee, 2007), including information dissemination during political campaigns (Bakshy, Messing, \& Adamic, 2015) as well as crisis situations (Oh, Agrawal, \& Rao, 2013).

While re-sharing of high quality information may help create a well-informed society, re-sharing of content that contains poor quality, inaccurate, or intentionally misleading information can have negative consequences, such as the spread of fake news (Polansky, Heimann, Schiller, \& Morgan, 2017). While the very definition of fake news, the role of social media in the spread of fake news, and the effect of fake news on social and political outcomes remain the subject of debates (Allcott \& Gentzkow, 2017; Harford, 2017), various approaches to combatting fake news are being proposed. These range from the use of human fact checkers for tracking fake news sites and informing social media users about potentially false content to applications of big data analytics and artificial intelligence algorithms for identification and suppression of false content (Eastwood, 2017). Yet, given the importance of the human factor in the spread of fake news, effective measures for combatting the dissemination of fake news requires a deep understanding of how information quality factors in individuals' decisions to re-share social media content.

Whereas significant research has focused on individual level determinants of information disclosure behavior, research on re-sharing has focused primarily on the effects of the structural properties of information dissemination networks (A. Lee, Yang, Tsai, \& Lai, 2014; Mendoza, Poblete, \& Castillo, 2010). In the light of the recent attention to the role of social media in the dissemination of fake news (Allcott \& Gentzkow, 2017), it is important to understand the relationship between the characteristics of the social media content and re-sharing behavior. This study seeks to examine individual level antecedents of information re-sharing behavior including individual beliefs about the quality of information available on SNS, attitude towards SNS use and risk perceptions and attitudes.

Specifically, the goal of this this study is to answer the following research questions:

- What is the relationship between perceived SNS information quality and information resharing?

- What is the relationship between individuals' risk-taking propensity and information resharing on SNS?

The research model proposed here helps explain re-sharing behavior using factors such as perceived information quality and risk propensity. This study tests the proposed model using survey data collected from users of SNSs. The results of the study provide insights into re-sharing behavior and have important implications for research and practice that are discussed in the discussion section. 


\section{LITERATURE REVIEW}

\section{SOCIAL NETWORKING USE}

Behavior of SNS users is influenced by situational factors, characteristics of a particular SNS environment, and individual characteristics of the users, known as intrinsic and extrinsic factors (Lin \& $\mathrm{Lu}, 2011)$. Because people are aware of their intentions to use SNS (Lu \& Yang, 2013), much of the research in SNS usage has been informed by the Theory of Planned Behavior (TPB) (Ajzen, 1991; Pelling \& White, 2009), the theory of reasoned action (Ajzen \& Fishbein, 1980; Valente, Gallaher, \& Mouttapa, 2004), and the derivative models, including TAM and UTAUT models (Davis, 1986, 1989; Kwon \& Wen, 2010; Sykes, Venkatesh, \& Gosain, 2009; Venkatesh, Morris, Davis, \& Davis, 2003). As predicted by TPB and TAM, usage intentions are a strong predictor of SNS use (Baker \& White, 2010), therefore, the usage intention construct is used as a proxy for the actual usage in IS research (Taylor \& Todd, 1995; Van der Heijden, 2003; Venkatesh et al., 2003) and in SNS usage studies (Kwon \& Wen, 2010). SNS usage behaviors vary widely and include such behaviors as online social interaction and communication (Sykes et al., 2009), relationship maintenance (Utz, 2015), information seeking and exchange (Borgatti \& Cross, 2003), information self-disclosure (Chen, 2013), location disclosure (Koohikamali, Gerhart, \& Mousavizadeh, 2015), content sharing (Z. Shi, Rui, \& Whinston, 2014), mongering (rumoring) (Koohikamali \& Kim, 2016; Oh et al., 2013), and entertainment (C. Lee \& Ma, 2012). SNS behaviors can be differentiated into three main categories: directed communication with individuals, passive consumption of social news, and broadcasting (Xie, 2014). The variety of SNS usage behaviors is reflected in the different conceptualization and operationalization of the SNS usage and usage intentions. Specifically researchers examined usage behaviors such as continuance use (N. Shi, Lee, Cheung, \& Chen, 2010), information disclosure (Posey, Lowry, Roberts, \& Ellis, 2010), identity construction (Zhao, Grasmuck, \& Martin, 2008), and customers' engagement (Chu \& Kim, 2011). Because usage intentions are related to actual usage behavior (Venkatesh et al., 2003), SNS usage intentions are used as a dependent variable in the research on the SNS user behavior and preferences (Bansal, Zahedi, \& Gefen, 2010; Kuss \& Griffiths, 2011; Pelling \& White, 2009).

TPB, TRA, and TAM models posit that attitudes towards a behavior are strong predictors of behavioral intentions TAM models theorize that attitudes towards IS use are influenced by individuals' perceptions of usefulness and ease of use of the system, as well as social norms regarding using the system (Davis, 1986, 1989). In the context of SNS use, attitudes towards using SNSs influence behavioral intention to use SNSs (Lowry, Cao, \& Everard, 2011). Attitudes towards using SNS are, in turn, influenced by privacy concerns (Lowry et al., 2011), social network structure (Peng, Fan, \& Dey, 2011), social identity (Dholakia, Bagozzi, \& Pearo, 2004), gender (Hargittai, 2007; Koohikamali, Peak, \& Prybutok, 2017), and cultural differences (Kim, Sohn, \& Choi, 2011).

Later versions of TAM, as well as UTAUT models, have dropped the attitude construct, posing instead that intentions to use an IS are influenced directly by individuals' beliefs about the IS usefulness (performance expectancy), IS ease of use (effort expectancy), social norms (social influence), and facilitating conditions (Venkatesh et al., 2003). Consistent with TAM and UTAUT models, belief about SNS usefulness, social norms, satisfaction, enjoyment, and prior experiences influence SNS usage intentions (Chang \& Zhu, 2012; C. Lee \& Ma, 2012; Lin \& Lu, 2011) and social norms influence intentions to adopt and use SNSs (Baker \& White, 2010; Chang \& Zhu, 2012) SNS continuance intention is influenced by SNS users' satisfaction about the SNS use (Chang \& Zhu, 2012), as well as perceived usefulness and enjoyment (Lin \& Lu, 2011). Intentions to share news on SNSs are correlated with prior SNS users' experiences (C. Lee \& Ma, 2012). 


\section{INFORMATION SHARING ON SNS}

Social network sites give their users an ability to create contents and share this with others. Intentional and voluntary sharing of personal information with others is commonly referred to as selfdisclosure (Chen, 2013; Posey et al., 2010). Self-disclosure includes sharing of personal information such as dispositions, states, events, home addresses, phone numbers, relationship statuses, personal photos and videos, and locations (Chen, 2013). Self-disclosure behavior can be characterized by its intent, as well as by the amount, honesty, depth, and valence of the disclosed information (Posey et al., 2010). Consistent with TPB, self-disclosure intentions are influenced by perceived benefit, perceived risk, privacy concerns, information control, and sensitivity (Xu, Michael, \& Chen, 2013). Other motivating factors for information disclosure include internet trust, personal internet interest (Dinev \& Hart, 2006), social validation, self-expression, relational development (Bazarova \& Choi, 2014), and entertainment (Utz, 2015). Privacy-related factors such as privacy concerns, privacy attitudes, and privacy practices have been cited as primary inhibitors of self-disclosure behavior (Chen, 2013; Tschersich \& Botha, 2013; Zlatolas, Welzer, Heričko, \& Hölbl, 2015). Notably, motivating factors appear to be stronger predictors of self-disclosure behavior that the inhibitors. For example, perceived convenience in relationship maintenance has a stronger influence on self-disclosure behavior than perceived privacy risk (Krasnova, Spiekermann, Koroleva, \& Hildebrand, 2010), and perceived benefit has a stronger effect on self-disclosure intentions than privacy concerns (Xu et al., 2013).

\section{INFORMATION RE-SHARING}

Taking advantage of SNA functionality, SNS users can re-share contents shared by their connections with minimal effort. Content re-sharing process involves a content's creator, a sharer, and connections of the sharer (Z. Shi et al., 2014). When SNS users share content with their connections, such content is likely to be re-shared by its recipients (Kane, Alavi, Labianca, \& Borgatti, 2014). As connections of a sharer can also act as sharers, a sharer of content often does not have a direct connection with the content creator (Viswanath, Mislove, Cha, \& Gummadi, 2009). Due to the transitivity of SNSs' structures, re-sharing practices may result in the dissemination of information beyond the circle of its intended recipients (Kane et al., 2014). For example, when a tweet is retweeted it reaches an average of 1000 users even for a person with low number of followers (Kwak, Lee, Park, \& Moon, 2010).

Although the practice of information re-sharing predates SNS applications (retweeting is an equivalent of email forwarding, which existed long before the creation of Twitter (Boyd, Golder, \& Lotan, 2010), the speed and the scale of SNS-based content re-sharing makes information dissemination using SNS qualitatively different from earlier information disseminations models (Oh et al., 2013). SNS-based content re-sharing, such as retweeting, contributes to a conversation ecology and brings new people into a specific strand, indirectly motivating them to participate (Boyd et al., 2010). It also implies a form of validating the content and engaging with others (Boyd et al., 2010). In spite of the important social consequences of information re-sharing, little research exists regarding factors that influence individuals' intentions to re-share content.

\section{PERCEIVED INFORMATION QUALITY}

The emergence of SNS as a major platform for information dissemination, and consequently as a key informational resource, makes it necessary to consider SNS content from a perspective of information quality (Pradhan \& Gay, 2013). The issue of information quality, as well as perceived information quality of internet resources, has attracted significant attention following the proliferation of corporate and personal websites in 1990s (Flanagin \& Metzger, 2000). Information quality is a multi-dimensional construct, and several models for the conceptualization and measurement of information quality exist (Eppler \& Wittig, 2000; Miller, 1996; Zmud, 1978). Miller (1996) relates information quality to the degree to which information users' needs are addressed and lists ten dimen- 
sions for information quality: accuracy, timeliness, completeness, coherence, format, accessibility, compatibility, security, and validity. The AIM Quality methodology for information quality assessments identifies four key quality components: intrinsic, contextual, representational, and accessibility (Y. Lee, Strong, Kahn, \& Wang, 2002). The IS success model defines five dimensions of contextual information quality, including completeness, ease of understanding, personalization, relevance, and security (Delone \& McLean, 2003). Information quality is an important predictor of information satisfaction, attitude towards IS use, IS usage intentions, system adoption, and system use (Delone \& McLean, 2003; Ghasemaghaei \& Hassanein, 2015; Nicolaou, Ibrahim, \& Van Heck, 2013; Wixom \& Todd, 2005).

In the context of Internet use, where users have limited ability to ascertain the actual quality of information, perceptions of information quality play an important role (Nicolaou \& McKnight, 2006; Yang, Cai, Zhou, \& Zhou, 2005). Research suggests that perceived information quality is highly situational and depends on the source and content of information (Castillo, Mendoza, \& Poblete, 2011; Johnson \& Kaye, 2004; Metzger, Flanagin, \& Medders, 2010). Such view is relevant to examining the role of information quality in the context of SNS use. Information content on social media includes photo and video content, user-generated text, links to web sites, and system-generated content such as location information. One of the distinguishing characteristics of user-generated contents is large variation in information quality (Agichtein, Castillo, Donato, Gionis, \& Mishne, 2008; Yang et al., 2005).

\section{RISK-TAKING PROPENSITY}

Individuals have different tendencies toward taking or avoiding risks, and risk-taking propensity describes how individuals deal dealing with uncertainties and their readiness to bear risk (Ahmed, 1985). Risk-taking propensity is defined as individuals' willingness and dispositions to take risks in different situations (Magdalena, 1977). Risk-taking propensity is a non-stable and non-constant dispositional attribute that can change over time (Sitkin \& Weingart, 1995). Literature suggests that decision makers exhibit more risk-taking propensity (are more risk-seeking) when pursuing positive opportunities (March \& Shapira, 1987). In addition to its positive effect on risky decision (Sitkin \& Weingart, 1995), risk propensity has been shown to reduce the perception of risks in the context of email use (Chen, Wang, Herath, \& Rao, 2011).

\section{THEORETICAL BACKGROUND AND RESEARCH MODEL}

\section{INFORMATION RE-SHARING AS AN ACT OF INFORMING}

Before researchers examine the theoretical frameworks that can help to understand the antecedents of information reshoring behavior, it is important to consider information re-sharing on SNS in the context of the Informing Science framework (Cohen, 2009). Grounded in Shannon and Weaver's communication model (1949), the informing science framework views the act of informing as a transmission of a message from a sender to a client(s) over a medium. In addition, drawing on Wilson's work on information seeking (1981), the informing science framework explicitly recognizes that social and environmental factors, as well as psychological characteristics of the sender and the client play an important role in the informing process as they influence the framing of the message. Specifically, the context in which the message is received as well as information about the sender of the message may influence how the message is framed by the client (receiver of the message). SNS platforms serve as the medium through which the message is transmitted, but also as a macro-informer that provides its users with information about the context and the sender (Evangelopoulos, Magro, \& Sidorova, 2012). As a result, every time a user encounters content on SNS, such a user can be viewed as a client in the act of informing. Such a user (client) becomes informed not only about the content of the message as intended by the sender but also about the sender, the social characteristics of his SNS environment, as well as the level of noise associated with SNS as a medium. Such information is 
expected to influence how future messages received by the users from the same or other senders in the SNS environment are framed. From the informing science framework point of view, information re-sharing can be viewed as co-joining of two informing acts, where the focal actor first acts as a client. Then, depending on the framing of the received message, the client may act as a sender and transmit the message to additional clients with or without reframing it (adding may be used to reframe the content before re-sharing) (Figure 1).

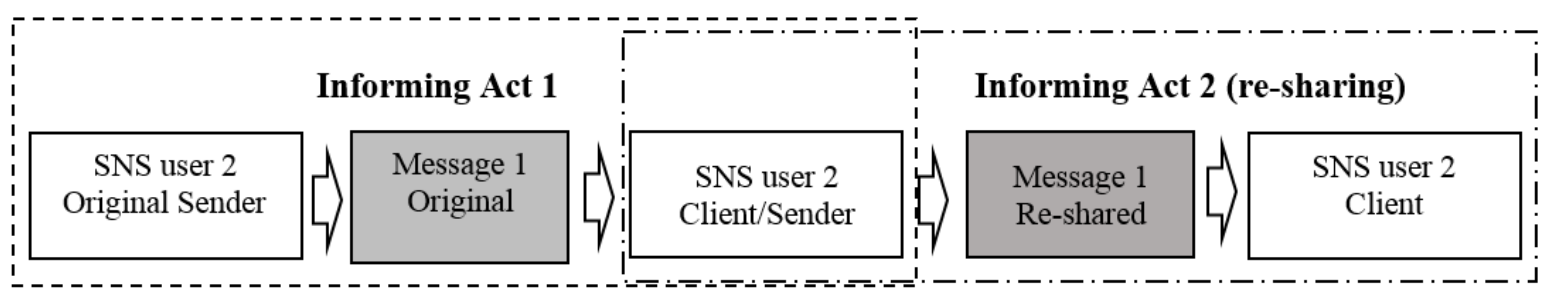

Figure 1. Information re-sharing framework

\section{ANTECEDENT OF INFORMATION RE-SHARING}

Information re-sharing behavior is an IT post-adoption behavior, whereby users who have adopted the social networks re-share the information being shared by others. As such, the re-sharing behavior is expected to be influenced by factors outlined in TPB, including attitude towards the behavior, as well as perceived behavioral control and subjective norms (Kautonen, Gelderen, \& Fink, 2013). Resharing is also a risky behavior, potentially associated with negative reputational outcomes. Therefore, it is likely to be influenced by individual risk perceptions and risk-taking propensity (Chen et al., 2011; Sitkin \& Pablo, 1992). Information quality has been shown to be an antecedent of perceived risk associated with system use in the context of organizational data interchange systems (Nicolaou et al., 2013). In addition, information quality is considered a key determinant of system usage intentions in general, according to the IS success model (Delone \& McLean, 2003). Because reputational benefits and risks associated with information re-sharing depend on whether the shared information is perceived as valuable and correct by the sharer's connections, perceived information quality is expected to be an important factor influencing information sharing intentions. Drawing on the model of determinants of risk behavior (Chen et al., 2011; Sitkin \& Pablo, 1992), TPB and research on information quality, this research proposes that individual's intentions to re-share information on SNS are influenced by the interplay of information quality perceptions, individual's risk propensity, as well the overall attitude towards using SNS. The complete research model is presented in Figure 2.

Perceived high-quality information is information that is perceived valuable to its users (Eppler \& Wittig, 2000). Information is of value if makes a difference and leads such a user to alter her/his behavior or way of thinking (McKinney \& Yoos, 2010). For that, information needs to be relevant to that particular user.

Perceived information relevance is defined as the pertinence of the informational content to the enduser. Relevance is often dependent on users' interests, and information that is relevant for some users may be irrelevant for others (De Choudhury, 2011, p.619). When SNS users encounter content on the SNS, they are expected to assess the relevance of that content for themselves as well as for connections in their network. If the information is perceived as relevant, and thus of value, the user will perceive the time spent on SNS acquiring and assimilating such information as well spent. This is expected to result in improved attitudes towards SNS user in general. On the contrary, if information content encountered by the user on SNS is deemed irrelevant, the user will view his time on SNS as a waste of time, thus leading to a less positive attitude towards SNS use.

H1: Perceived information relevance is related to attitude toward using SNSs in a positive direction. 


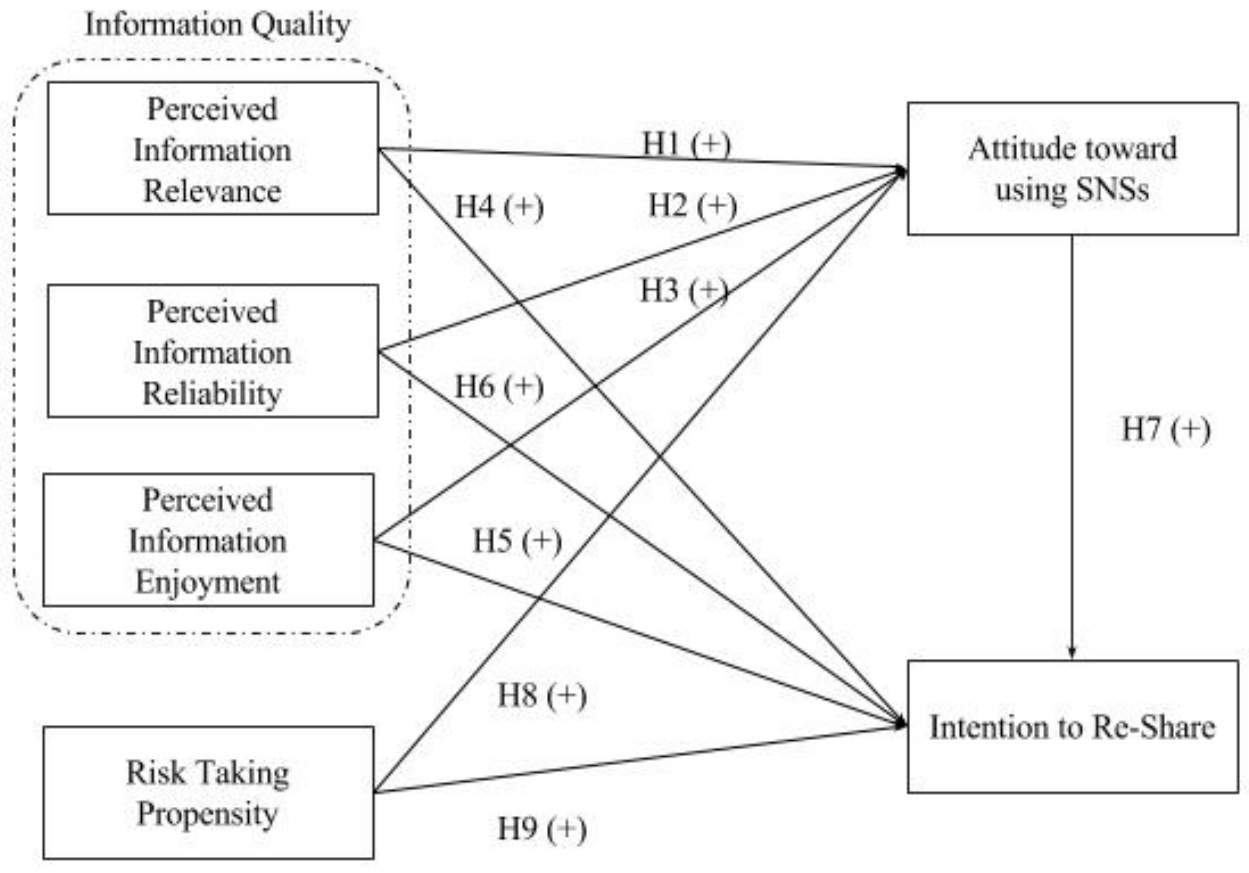

Figure 2. The research model of information re-sharing

Information is reliable when it is correct and fault free (Naumann \& Rolker, 2000). However, because SNS users rarely have an opportunity to ascertain the correctness of information, they may perceive information as reliable if they have confidence in the reliability of the information source (Knight \& Burn, 2005). If information content is perceived as reliable, it offers higher value to the users, as the user can act upon such information with higher confidence. Users who perceive information available on their social network as reliable, and thus more actionable, will view their time spend on SNS obtaining such information as a value adding activity, and thus will have a more positive attitude towards SNS use in general. On the contrary, users who do not trust the information on their SNS as reliable will consider SNS use as an unproductive activity, and thus will have a less positive attitude towards SNS use.

H2: Perceived information reliability is related to attitude toward using SNSs in a positive direction.

In the context of hedonic SNS use, informational content may also be of value if consuming such content provides entertainment and elicits positive affective reactions from the SNS users. Information enjoyability reflects the degree to which consuming the information is perceived as pleasurable, fun and entertaining (Schaal, Smyth, Mueller, \& MacLean, 2012). To the extent that SNS users derive hedonic pleasure from information consumption on SNS, the use of the SNS will be considered as an activity that contributes positively to the overall well-being of the users, and users will have positive attitudes to SNS use. SNS information content that does not elicit positive affective reaction or that elicits negative affective reaction making users sad or angry will contribute to the overall dissatisfaction with SNS, and will result in the overall less positive attitudes towards SNS use.

H3: Perceived information enjoyability is related to attitude toward using SNSs in a positive direction.

Information relevance, reliability, and enjoyability are also expected to be pertinent to the users' decisions to re-share information. Re-sharing information that is relevant and/or enjoyable to others on the individual's social network is expected to result to messages and responses related to the reshared content, thus strengthening the social ties between the user and his/her network, and thus 
contributing to the social capital of the user (Wasko \& Faraj, 2005). Because building social capital and maintaining social ties is one of the key reasons for SNS use (Xie, 2014), users are expected to re-share information that they perceive as relevant and/or enjoyable to members of their social network. Because users typically have a large number of SNS connections, and because many of their connections typically have common interests, users are expected to consider information that is relevant and enjoyable to them to be relevant and enjoyable to their connections. Consequently, it is expected that users are likely to re-share information that they consider relevant.

H4: Perceived information relevance is related to intention to re-share in a positive direction.

H5: Perceived information enjoyability is related to intention to re-share in a positive direction.

Users' perception of information reliability is expected to play a role in their decision to re-share the information. When information is unreliable, the user re-sharing such information can expect to incur reputational loss if the inaccuracy of such information is uncovered and publicly exposed by his/her connections. SNS users are concerned about their online reputation and image. Indeed, online reputation management has become a common practice for internet users (Madden \& Smith, 2010). Consequently, SNS users are expected to avoid behaviors that have a negative effect on their online reputation, such as intentionally propagating information that they consider un-reliable.

H6: Perceived information reliability is related to intention to re-share in a positive direction.

Information re-sharing is a type of SNS usage behavior, therefore, according to TPB (Ajzen, 2011), individuals with a more positive attitude towards SNS use are expected to be more likely to engage with the re-sharing behavior. In addition, unlike passive information consumption, information resharing, along with other types of information disclosure on SNS is observable publicly. Individuals with a more positive attitude towards SNS use are likely to want to be seen by others as active SNS users, and thus will engage in information re-sharing more actively. Individuals with a negative attitude towards SNS use are expected to avoid being "caught" using SNS, and thus are less likely to engage in publicly observable SNS usage behavior such as information re-sharing.

H7: Attitude toward using SNSs is positively related to intention to re-share.

SNS use in general, as well as information re-sharing in particular, is associated with risks, reputational and other, to its users (Hansen, Møller-Jensen, \& Stubbe-Solgaard, 2004). Risk-taking behaviors involve achieving a balance between perceived positive and negative consequences of performing a behavior (Aklin, Lejuez, Zvolensky, Kahler, \& Gwadz, 2005), and individuals differ with respect to the degree to which they are willing to take risk (Sitkin \& Weingart, 1995). Individuals with higher risk-taking propensity are comfortable with a relatively higher level of risk than low-risk-propensity individuals and typically engage in more risky behaviors (Chen et al., 2011).

Research on risk taking behavior suggests that risk-taking propensity is negatively related to risk perceptions (Chen et al., 2011; Sitkin \& Pablo, 1992). Risk-averse individuals, i.e., individuals with low risk-taking propensity, tend to focus more on examining potential negative outcomes (losses) compared to risk-seeking individuals who tend to focus more on examining potential positives outcomes (gains). The increased salience of potential losses vis-à-vis potential gains results in the overestimation of the probability of losses and the underestimation of the probability of gains by risk-averse individuals. Similarly, the increased saliency of gains drives risk-seeking individuals to underestimate the probability of losses and to overestimate the probability of gains (Sitkin \& Pablo, 1992). As a result, it is expected that individuals with higher risk-taking propensity are likely to under-estimate the risks associated with SNS use in relation to its benefits, compared to low risk propensity individuals. Therefore, high-risk-propensity individuals are likely to have a more positive attitude towards SNS use that low-risk-propensity individuals.

H8: Risk taking propensity is positively correlated with attitude to use SNSs. 
Similarly, individuals with high risk propensity are expected to underestimate the reputational and other risks associated with information re-sharing and, thus, are more likely to engage in information re-sharing behaviors, compared to low risk propensity individuals.

H9: Risk taking propensity is positively correlated with intention to re-share information on SNSs.

\section{METHODOLOGY}

To explain the antecedents of shared information about others, this research proposes a model of information re-sharing. This model draws on TPB and Delone and McLean's (2003) IS success model to explain how perceived information quality influences intentions to re-share information on SNSs.

\section{SURVEY ADMINISTRATION}

A survey was administered to test the research model. Data from undergraduate students in a public university in the US was collected. Student samples are appropriate for this study because according to the Pew research center, $75 \%$ of college students use Facebook, one of the most famous social networks (Duggan \& Smith, 2014). In addition, today teens share more information on social media than they did in the past (Madden, Lenhart, \& Cortesi, 2013). This study focuses on the information re-sharing behavior on SNSs and undergraduate students are appropriate representative of the whole population. The descriptive of demographic information of respondents is reported in Table 1. A total of 456 respondents filled out the survey, and after excluding non-users and incomplete data, a total of 379 valid responses were used. A breakdown of invalid and removed responses is reported in Appendix A.

Table 1. Demographic information

\begin{tabular}{|l|l|l|l|l|l|}
\hline Gender & \multicolumn{4}{l|}{ Male (52\%); Female (48\%) } \\
\hline Age & \multicolumn{4}{l|}{$80 \%$ of respondents are within age group18-25 years. } \\
\hline Dispensable Income per year & $70 \%$ of respondents have less than \$10000 dispensable income. \\
\hline Academic Status & Freshman & Sophomore & Junior & Senior & Graduate \\
& $(37 \%)$ & $(24 \%)$ & $(15 \%)$ & $(9 \%)$ & $(15 \%)$ \\
\hline
\end{tabular}

Survey respondents identified the following SNS as most frequently used: Facebook (identified by $49 \%$ of respondents), Instagram (23\%), and Twitter (16\%). Nine percent of respondents reported re-sharing content more than 15 times per week, 53\% of respondents reported re-sharing information 1-5 times per week, and $22 \%$ of respondents reported not re-sharing content. The top three most re-shared content types included images (reported by $41 \%$ of respondents), news (reported by $15 \%$ of respondents), and videos (reported by $14 \%$ of respondents).

\section{DATA ANALYSIS AND RESULTS}

The authors tested the posited model's partial least squares (PLS) analysis. PLS employs a component-based approach for estimation that minimizes residual distributions (Chin, 1998) and is wellsuited for testing complex relationships by avoiding inadmissible solutions and factor indeterminacy (Chen et al., 2011). PLS focuses on the explained variance of dependent variable, which is appropriate for exploratory research theories (Hair, Hult, Ringle, \& Sarstedt, 2013). Smart PLS 3.2.4 is used to test the research model, calculating t-tests for each path. A three-step analysis procedure was imple- 
mented: measurement model reliability and validity assessment, common method bias checking, and evaluation of structural model.

\section{EXPLORATORY FACTOR ANALYSIS}

The exploratory factor analysis (EFA) was used to know whether measurement items represent underlying constructs or not (Ford, MacCallum, \& Tait, 1986). Using the Varimax rotation, items with low loadings or high cross loadings were removed from further analysis. All factors loaded greater than 0.5 on one of the nine factors and greater than outer loadings on other factors. The results indicating that all factor loadings are greater than the recommended benchmark of 0.7 (Henseler, Ringle, \& Sinkovics, 2009). Thus, all items were used to perform the hypothesized model fit process. The factor loading result is shown in Appendix B.

\section{MEASUREMENT MODEL RELIABILITY AND VALIDITY}

The adequacy of the measurement model is tested in three steps: examining measurement reliability (composite and indicator reliabilities), convergent validity, and discriminant validity (Hair et al., 2013; Hulland, 1999). Table 2 presents descriptive statistics, correlations, composite reliability values, Cronbach's alpha values, and the AVEs (average variance explained) of principal constructs.

First, measurement reliability is verified using composite reliability and Cronbach's alpha values. Composite reliability is established if all calculated values exceed 0.70 (Fornell \& Larcker, 1981; Nunnally, Bernstein, \& Berge, 1967). Also, Cronbach's alpha scores of 0.70 or greater are considered acceptable (Nunnally et al., 1967), and scores between 0.8 and 0.9 are considered satisfactory (Henseler et al., 2009). Table 2 shows all composite reliabilities and Cronbach's alpha values exceed 0.70 , verifying measurement reliability. Second, convergent validity is established by considering outer loadings or the AVEs (Hair et al., 2013). Convergent validity is proven if AVEs reach at least 0.50 and if principal hypothesized constructs load higher than other constructs (Chin, 1998). Table 2 shows all AVEs exceed 0.50 and inter-item loadings are higher than outer loadings, thus establishing convergent validity (see Appendix B for details). Third, discriminant validity is verified by ensuring an indicator's outer loading on a construct is greater than cross loadings with other constructs, and then by ensuring for each construct the square root of AVE is higher than the outer correlations (Hair et al., 2013). According to the item loading analysis in Appendix B and Table 2 analysis, all outer loadings are greater than cross loadings for each construct and squared root of AVEs are higher than outer correlations. The results affirm discriminant validity. Overall, results demonstrate a high reliability and validity of the posited measurement model.

Table 2. Descriptive statistics, correlations, and average variance extracted

\begin{tabular}{|c|c|c|c|c|c|c|c|c|c|c|c|c|}
\hline \multicolumn{2}{|r|}{ Principal Construct } & \multirow{2}{*}{\begin{tabular}{|c|} 
Mean \\
4.98 \\
\end{tabular}} & \multirow{2}{*}{\begin{tabular}{|l|} 
SD \\
1.07 \\
\end{tabular}} & \multirow{2}{*}{\begin{tabular}{|l|} 
CR \\
0.95 \\
\end{tabular}} & \multirow{2}{*}{$\begin{array}{l}\mathbf{C A} \\
0.93\end{array}$} & \multirow{2}{*}{$\begin{array}{c}\text { AVE } \\
0.79\end{array}$} & \multirow{2}{*}{$\begin{array}{c}1 \\
0.89\end{array}$} & \multirow[t]{2}{*}{2} & \multirow[t]{2}{*}{3} & \multirow[t]{2}{*}{4} & \multirow[t]{2}{*}{5} & \multirow[t]{2}{*}{6} \\
\hline 1 & Attitude (ATT) & & & & & & & & & & & \\
\hline 2 & Perceived information enjoyability (ENJ) & 5.55 & 0.94 & 0.91 & 0.85 & 0.77 & 0.63 & 0.88 & & & & \\
\hline 3 & Intention to re-share (INT) & 5.11 & 1.34 & 0.96 & 0.95 & 0.82 & 0.60 & 0.53 & 0.91 & & & \\
\hline 4 & Perceived information relevance (REL) & 4.02 & 1.39 & 0.98 & 0.97 & 0.94 & 0.51 & 0.56 & 0.42 & 0.97 & & \\
\hline 5 & Perceived information reliability (RELI) & 3.15 & 1.36 & 0.94 & 0.91 & 0.85 & 0.43 & 0.45 & 0.35 & 0.54 & 0.92 & \\
\hline 6 & Risk taking propensity (RIP) & 4.72 & 1.06 & 0.89 & 0.81 & 0.73 & 0.28 & 0.32 & 0.31 & 0.19 & 0.21 & 0.85 \\
\hline \multicolumn{13}{|c|}{ SD: Standard Deviation, CR: Composite Reliability, CA: Cronbach's alpha. } \\
\hline \multicolumn{13}{|c|}{ The diagonal elements (in bold) represent the square root of AVE. } \\
\hline \multicolumn{13}{|c|}{ Off-diagonal elements are the correlations among constructs. } \\
\hline
\end{tabular}




\section{COMMON METHOD BIAS}

Common method bias presents a potential validity threat in survey studies (Campbell \& Fiske, 1959). According to Harman's single factor test, common method bias may exist under two conditions. First, a single factor emerges from the un-rotated factor solution. Second, a single factor accounts for the majority of the variance within variables (Podsakoff, MacKenzie, Lee, \& Podsakoff, 2003). First, all the 22 items entered the explanatory factor analysis (EFA) and the un-rotated solution results in six total factors, which equals the number of latent variables in the posited model. Second, the six factors that emerged from the explanatory factor analysis account for $82 \%$ of variance in the data. However, the initial extracted factor accounts for less than $50 \%$ of the total variance (45\%). The explained variance of the seven extracted factors and their corresponding eigenvalues are the following: $45 \%($ eigenvalue $=4.26), 11.18 \%($ eigenvalue $=3.93), 8.59 \%($ eigenvalue $=2.79), 7.12 \%($ eigenvalue $=2.67), 5.71 \%$ (eigenvalue $=2.27)$, and $4.41 \%$ (eigenvalue $=2.12)$. Neither of two indicators for common method bias occurred in this study.

\section{STRUCTURAL MODEL ASSESSMENT}

The PLS results show that the structural model explains $44.5 \%$ of variance in attitude toward using SNSs and $41.4 \%$ in intention to re-share information. Thus, the posited model demonstrates satisfactory explanatory power to capture the SNS user intentions to re-share information. The PLS path coefficients are shown in Figure 3. Overall, the results provide evidence supporting the research model that is proposed.

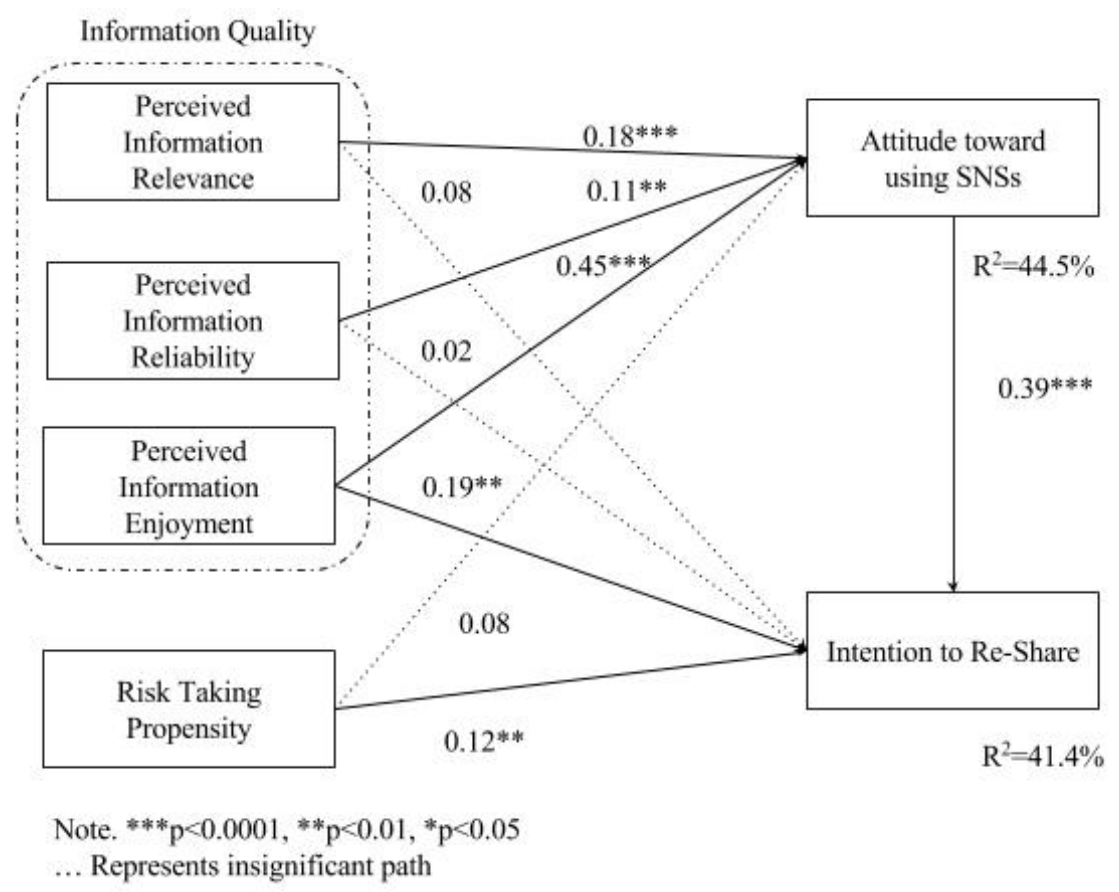

Figure 3. Information Re-Sharing (ISH) Model Results

The results indicate that perceived information relevance $(b=0.18, p<0.001)$, perceived information reliability $(\mathrm{b}=0.11, \mathrm{p}<0.01)$, and perceived information enjoyment $(\mathrm{b}=0.45, \mathrm{p}<0.001)$ are significant predictors of attitude toward SNSs, together explaining $44.5 \%$ of variance in the dependent variable. This provides support for hypotheses $\mathrm{H} 1, \mathrm{H} 2$, and $\mathrm{H} 3$. The relationship between risk taking propensity and attitude toward using SNSs was not found significant $(b=0.08, p>0.05)$; thus, hypothesis H8 was not supported. As hypothesized, perceived information enjoyment $(b=0.19, \mathrm{p}<0.01)$, risk taking propensity $(b=0.12, p<0.01)$, and attitude toward using SNS $(b=0.39, p<0.001)$ are all significantly correlated with intention to re-share information, providing support for hypotheses $\mathrm{H} 5, \mathrm{H} 7$, and $\mathrm{H}$ 9. 
The direct effects of perceived information relevance $(b=0.02, p>0.05)$ and perceived information reliability ( $b=0.08, \mathrm{p}>0.05)$ on intention were not found significant; thus, hypotheses H4 and H6 were not supported.

\section{DISCUSSION}

\section{FINDINGS}

This study investigates the influence of perceived information quality, perceived reputation risk, and risk-taking propensity on attitude toward using SNSs and intention to re-share information. As social media morph from a place to stay in touch and learn about personal lives of friends and family, to become the primary source of news and information about politics, the economy, the environment, the quality of the information content becomes more important. As information shared by SNS users ranges from personal updates to political and sensational information (Osatuyi, 2013), the quality of information shared is expected to influence various aspects of SNS user behavior. This study examines how users' perceptions of different aspects of information quality influence users' attitude towards SNS, as well as their intention to re-share information they see on SNS. Consistent with the predictions, all three aspects of information quality (i.e., information relevance, information reliability, and information enjoyment) were found to be significant predictors of attitude towards SNS use. This is consistent with extant research on IS use, which suggests that perceived information quality positively influence attitude towards IS (Wixom \& Todd, 2005).

Attitude towards using SNS was found to be a strong predictor of intentions to re-share, which is consistent with the notion that message framing by both sender and the receiver are influenced by the social context (Cohen, 2009). In addition, both perceived information enjoyment and risk-taking propensity were found to be significant predictors of the intentions to re-share information. This is consistent with prior research that suggests that perceived benefits are a stronger predictor of selfdisclosure intentions than privacy concerns (Xu et al., 2013). However, the results support the conjecture that SNS users view information re-sharing as a potentially risky activity, and users with higher risk-taking propensity are more likely to re-share information on SNS. This is in line with prior research that suggests that users understand that SNS use is associated with certain risks and take measures to mitigate such risks. For example, almost two thirds of young SNS users have modified their privacy setting to have more control over the information they share with others (Madden \& Smith, 2010).

Findings of this study contribute to the literature both theoretically and practically. From the theoretical point of view, this study is among the first to address the issue of information quality in the context of information re-sharing on social media. The model of information re-sharing (ISH) proposed here integrates aspects on the theory of planned behavior (TPB) (Ajzen, 2011) and of the IS success model (Delone \& McLean, 2003), and incorporates the risk propensity as an important predictor of a potentially risky behavior. Whereas to date, SNS use research has focused primarily on managing personal information and associated privacy concerns, this study moves the research agenda towards viewing SNS as a general-purpose information dissemination tool, where information quality plays a defining role. Yet, the results of the study suggest that the aspects of information quality that are most important in the SNS context may be different from those defining IS use in other contexts. For example, findings of this research suggest that information enjoyment is the only aspect of information quality that was found to be an important predictor not only of attitude towards SNS use, but also of the intention to re-share information. Notably, this aspect of information quality is hedonically focused and is not considered critical in other IS use contexts (Wixom \& Todd, 2005).

This study has important practical implications for SNS users and providers alike. Ensuring that information available on SNS is of high quality is critical to maintaining a healthy user base. Therefore, SNS providers need to take particular care to prevent the erosion of information quality on their sites due to a high number of hoaxes and trolling (Stein, 2016). Individual business users of SNS can 
make information about their products to be more 're-sharing ready' by making it more enjoyable to view such information.

This study contributes to the interdisciplinary field of informing science in two key ways. First, it conceptualizes the act of informing not as an atomic transaction of passing a message from a sender to a client, but as multi-stage process of information dissemination in which a client of one informing transaction becomes a sender and passes the message to other clients. Second, the study highlights the importance of the overall context in which the informing act takes place in shaping the decision by a client to act as a sender and thus contribute to the dissemination of the message. Finally, by bringing information quality into the focus of the discourse on informing, this research highlights the need to consider the outcomes of informing (such as the spread of fake news) as a part of the informing science framework.

\section{LIMITATIONS AND FUTURE RESEARCH}

Findings of this study should be interpreted with regard to certain limitations. First, like most of other survey methods, the cross-sectional data is limited in its ability to detect causality, therefore it is impossible to determine whether information quality perceptions influence attitude towards SNS or are a consequence of a more positive attitude. Therefore, this study suggests that further research into the role of information quality employs other methods such as experiments to ascertain the causal nature of the relationships.

Second, recent studies in IS research have tried to differentiate between the initial-adoption and postadoption behaviors by elucidating IS continuance behavior. IS habit is defined to explain the extent people use IT automatically due to learning (Limayem, Hirt, \& Cheung, 2007). Consequently, habits may limit the predictive power of intentions in IS usage and continuance. Verplanken (2006) defined habit as behavior automaticity in stable contexts. Unlike most habit-behavior studies in organizational contexts, social networks are not stable contexts. Social networks are dynamic contexts (McDonald, 2007). Because on social networks there is a variability in terms of information being shared, users' network characteristics, and network sizes, re-sharing behavior is not derived automatically from learning and it requires aware cognitive behavior. Future research could extend the effect of habit on information re-sharing behavior by conducting longitudinal experiments.

\section{CONCLUSION}

This study serves as an initial attempt to investigate the information re-sharing on social network sites. Informed by the informing science framework and grounded in the theory of planned behavior and information sharing literature, the research models presented here delineate the effects of perceived information quality and perceived reputation risk on a user's attitude to use SNSs and re-share information on SNSs. Findings of this research suggest that perceived information quality influences both attitude toward using SNSs and intention to re-share information. However, risk-taking propensity only influences the attitude toward using SNSs. Findings demonstrate that when SNS users perceive higher risks to their reputation they may have less attitude to use them.

\section{REFERENCES}

Agichtein, E., Castillo, C., Donato, D., Gionis, A., \& Mishne, G. (2008). Finding high-quality content in social media. In International Conference on Web Search and Data Mining (pp. 183-193). https://doi.org/10.1145/1341531.1341557

Ahmed, S. U. (1985). Nach, risk-taking propensity, locus of control and entrepreneurship. Personality and Individual Differences, 6(6), 781-782. https://doi.org/10.1016/0191-8869(85)90092-3

Ahn, Y.-Y., Han, S., Kwak, H., Moon, S., \& Jeong, H. (2007). Analysis of topological characteristics of huge online social networking services. In Proceedings of the 16th International Conference on World Wide Web (pp. 835-844). https://doi.org/10.1145/1242572.1242685 
Information Re-Sharing on Social Network Sites

Ajzen, I. (1991). The theory of planned behavior. Organizational Behavior and Human Decision Processes, 50(2), 179211.

Ajzen, I. (2011). Theory of planned behavior. In P. A. M. Van Lange, A. W. Kruglanski, \& E. T. Higgins (Eds.), Handbook of theories of social psychology (Vol. 1, p. 568). VU University Amsterdam, Netherlands.

Ajzen, I., \& Fishbein, M. (1980). Understanding attitudes and predicting social behavior. Englewood Cliffs, NJ: Prentice-Hall.

Aklin, W. M., Lejuez, C. W., Zvolensky, M. J., Kahler, C. W., \& Gwadz, M. (2005). Evaluation of behavioral measures of risk taking propensity with inner city adolescents. Bebaviour Research and Therapy, 43(2), 215228.

Allcott, H., \& Gentzkow, M. (2017). Social media and fake news in the 2016 election. Journal of Economic Perspectives, 31(2), 211-236. https://doi.org/10.3386/w23089

Baker, R. K., \& White, K. M. (2010). Predicting adolescents' use of social networking sites from an extended theory of planned behaviour perspective. Computers in Human Behavior, 26(6), 1591-1597.

Bakshy, E., Messing, S., \& Adamic, L. A. (2015). Exposure to ideologically diverse news and opinion on Facebook. Science, 348(6239), 1130-1132. https://doi.org/10.1126/science.aaa1160

Bansal, G., Zahedi, F., \& Gefen, D. (2010). The impact of personal dispositions on information sensitivity, privacy concern and trust in disclosing health information online. Decision Support Systems, 49(2), 138-150.

Bazarova, N. N., \& Choi, Y. H. (2014). Self-disclosure in social media: Extending the functional approach to disclosure motivations and characteristics on social network sites. Journal of Communication, 64(4), 635-657.

Bhattacherjee, A., \& Premkumar, G. (2004). Understanding changes in belief and attitude toward information technology usage: A theoretical model and longitudinal test. MIS Quarterly, 28(2), 229-254.

Borgatti, S. P., \& Cross, R. (2003). A relational view of information seeking and learning in social networks. Management Science, 49(4), 432-445.

Boyd, D., Golder, S., \& Lotan, G. (2010). Tweet, tweet, retweet: Conversational aspects of retweeting on twitter. In 43rd Hawaii International Conference on System Sciences (HICSS), 2010 (pp. 1-10). IEEE.

Campbell, D. T., \& Fiske, D. W. (1959). Convergent and discriminant validation by the multitrait-multimethod matrix. Psychological Bulletin, 56(2), 81.

Castillo, C., Mendoza, M., \& Poblete, B. (2011). Information credibility on twitter. In Proceedings of the 20th international conference on World wide web (pp. 675-684). ACM.

Chang, Y. P., \& Zhu, D. H. (2012). The role of perceived social capital and flow experience in building users' continuance intention to social networking sites in China. Computers in Human Behavior, 28(3), 995-1001.

Chen, R. (2013). Living a private life in public social networks: An exploration of member self-disclosure. Decision Support Systems, 55(3), 661-668. https://doi.org/10.1016/j.dss.2012.12.003

Chen, R., Wang, J., Herath, T., \& Rao, H. R. (2011). An investigation of email processing from a risky decision making perspective. Decision Support Systems, 52(1), 73-81.

Chin, W. W. (1998). Commentary: Issues and opinion on structural equation modeling. MIS Quarterly, 22(1), viixvi.

Chu, S.-C., \& Kim, Y. (2011). Determinants of consumer engagement in electronic word-of-mouth (eWOM) in social networking sites. International Journal of Advertising, 30(1), 47-75.

Cohen, E. B. (2009). A philosophy of Informing Science. Informing Science, 12, 1-15.

Davis, F. D. (1986). A technology acceptance model for empirically testing new end-user information systems: Theory and results. Management. Massachusetts Institute of Technology.

Davis, F. D. (1989). Perceived usefulness, perceived ease of use, and user acceptance of information technology. MIS Quarterly, 319-340. 
De Choudhury, M. (2011). Information quality and relevance in large-scale social information systems. In B. Furht \& A. Escalante (Eds.), Handbook of data intensive computing (pp. 617-635). Springer.

Delone, W. H., \& McLean, E. R. (2003). The DeLone and McLean model of information systems success: A ten-year update. Journal of Management Information Systems, 19(4), 9-30.

Dholakia, U. M., Bagozzi, R. P., \& Pearo, L. K. (2004). A social influence model of consumer participation in network-and small-group-based virtual communities. International Journal of Research in Marketing, 21(3), 241-263.

Dinev, T., \& Hart, P. (2006). An extended privacy calculus model for e-commerce transactions. Information Systems Research, 17(1), 61-80.

Duggan, M., \& Smith, A. (2014). Social media update 2013. Number, facts, and trends shaping the world (Vol. 5). Pew Research Center. Retrieved from http://pewinternet.org/Reports/2013/Social-Media-Update.aspx

Eastwood, G. (2017). How big data and AI can combat fake news. Retrieved from https://www.networkworld.com/article/3161228/artificial-intelligence/how-big-data-and-ai-can-combatfake-news.html

Eppler, M. J., \& Wittig, D. (2000). Conceptualizing information quality: A review of information quality frameworks from the last ten years. In Proceedings of the Fifth Conference on Information Quality (IQ 2000) (pp. 83-96).

Evangelopoulos, N., Magro, M. J., \& Sidorova, A. (2012). The dual micro/macro informing role of social network sites: Can twitter macro messages help predict stock prices? Informing Science: The International Journal of an Emerging Transdiscipline15, 247-267. Retrieved from https://www.informingscience.org/Publications/1739

Flanagin, A. J., \& Metzger, M. J. (2000). Perceptions of internet information credibility. Journalism \& Mass Communication Quarterly, 77(3), 515-540.

Ford, J. K., MacCallum, R. C., \& Tait, M. (1986). The application of exploratory factor analysis in applied psychology: A critical review and analysis. Personnel Psychology, 39(2), 291-314.

Fornell, C., \& Larcker, D. F. (1981). Evaluating structural equation models with unobservable variables and measurement error. Journal of Marketing Research, 18(1), 39-50.

Ghasemaghaei, M., \& Hassanein, K. (2015). Online information quality and consumer satisfaction: The moderating roles of contextual factors-A meta-analysis. Information \& Management, 52(8), 965-981.

Hair, J. F., Jr., Hult, G. T. M., Ringle, C., \& Sarstedt, M. (2013). A primer on partial least squares structural equation modeling (PLS-SEM). SAGE Publications.

Hansen, T., Møller-Jensen, J., \& Stubbe-Solgaard, H. (2004). Predicting online grocery buying intention: A comparison of the theory of reasoned action and the theory of planned behavior. International Journal of Information Management, 24(6), 539-550.

Harford, T. (2017). Hard truths about fake news. Retrieved from https://www.ft.com/content/3316daa2-fd44$\underline{11 \mathrm{e} 6-96 \mathrm{f} 8-3700 \mathrm{c} 5664 \mathrm{~d} 30}$

Hargittai, E. (2007). Whose space? Differences among users and non-users of social network sites. Journal of Computer-Mediated Communication, 13(1), 276-297.

Henseler, J., Ringle, C. M., \& Sinkovics, R. R. (2009). The use of partial least squares path modeling in international marketing. Advances in International Marketing, 20, 277-319.

Hulland, J. (1999). Use of partial least squares (PLS) in strategic management research: A review of four recent studies. Strategic Management Journal, 20(2), 195-204.

Johnson, T. J., \& Kaye, B. K. (2004). Wag the blog: How reliance on traditional media and the internet influence credibility perceptions of weblogs among blog users. Journalism \& Mass Communication Quarterly, 81(3), 622642.

Kane, G. C., Alavi, M., Labianca, G., \& Borgatti, S. P. (2014). What's different about social media networks? A framework and research agenda. MIS Quarterly, 38(1), 275-304. 
Kautonen, T., Gelderen, M., \& Fink, M. (2013). Robustness of the theory of planned behavior in predicting entrepreneurial intentions and actions. Entrepreneurship Theory and Practice, 39(3), 655-674.

Kim, Y., Sohn, D., \& Choi, S. M. (2011). Cultural difference in motivations for using social network sites: A comparative study of American and Korean college students. Computers in Human Behavior, 27(1), 365-372.

Knight, S., \& Burn, J. (2005). Developing a framework for assessing information quality on the world wide web. Informing Science:The International Journal of an Emerging Transdiscipline, 8, 159-172. Retrieved from https://www.informingscience.org/Publications/493

Koehorst, R. (2013). Personal information disclosure on online social networks. University of Twente, Enschede.

Koohikamali, M., Gerhart, N., \& Mousavizadeh, M. (2015). Location disclosure on LB-SNAs: The role of incentives on sharing behavior. Decision Support Systems, 71, 78-87.

Koohikamali, M., \& Kim, D. J. (2016). Rumor and truth spreading patterns on social network sites during social crisis: Big data analytics approach. Lecture Notes in Business Information Processing, 258. https://doi.org/10.1007/978-3-319-45408-5 15

Koohikamali, M., Peak, D., \& Prybutok, V. (2017). Beyond self-disclosure: Disclosure of information about others in social network sites. Computers in Human Behavior, 69, 29-42. https://doi.org/10.1016/i.chb.2016.12.012

Krasnova, H., Spiekermann, S., Koroleva, K., \& Hildebrand, T. (2010). Online social networks: Why we disclose. Journal of Information Technology, 25(2), 109-125.

Kuss, D. J., \& Griffiths, M. D. (2011). Online social networking and addiction-A review of the psychological literature. International Journal of Environmental Research and Public Health, 8(9), 3528-3552.

Kwak, H., Lee, C., Park, H., \& Moon, S. (2010). What is Twitter, a social network or a news media? In Proceedings of the 19th international conference on World wide web (pp. 591-600). ACM.

Kwon, O., \& Wen, Y. (2010). An empirical study of the factors affecting social network service use. Computers in Human Behavior, 26(2), 254-263.

Lee, A., Yang, F.-C., Tsai, H.-C., \& Lai, Y.-Y. (2014). Discovering content-based behavioral roles in social networks. Decision Support Systems, 59, 250-261.

Lee, C., \& Ma, L. (2012). News sharing in social media: The effect of gratifications and prior experience. Computers in Human Behavior, 28(2), 331-339.

Lee, Y., Strong, D., Kahn, B., \& Wang, R. (2002). AIMQ: A methodology for information quality assessment. Information \& Management, 40(2), 133-146. https://doi.org/10.1016/S0378-7206(02)00043-5

Limayem, M., Hirt, S. G., \& Cheung, C. M. K. (2007). How habit limits the predictive power of intention: The case of information systems continuance. MIS Quarterly, 31(4), 705-737.

Lin, K.-Y., \& Lu, H.-P. (2011). Why people use social networking sites: An empirical study integrating network externalities and motivation theory. Computers in Human Behavior, 27(3), 1152-1161.

Lowry, P. B., Cao, J., \& Everard, A. (2011). Privacy concerns versus desire for interpersonal awareness in driving the use of self-disclosure technologies: The case of instant messaging in two cultures. Journal of Management Information Systems, 27(4), 163-200.

Lu, H.-P., \& Yang, Y.-W. (2013). Toward an understanding of the behavioral intention to use a social networking site: An extension of task-technology fit to social-technology fit. Computers in Human Behavior, 34, 323-332.

Madden, M., Lenhart, A., \& Cortesi, S. (2013). Teens, social media, and privacy. Pew Internet \& American Life Project. Retrieved from http://www.lateledipenelope.it/public/52dff2e35b812.pdf

Madden, M., \& Smith, A. (2010). Reputation Management and Social Media. Pew Internet \& American Life Project. Washington, D.C. 20036: Pew Research Center. Retrieved from http://ictlogy.net/bibliography/reports/projects.php?idp $=1650$ 
Magdalena, F. V. (1977). The Filipino entrepreneurs of Hawaii: an inquiry into their roots and success. Sociology. University of Hawaii.

March, J. G., \& Shapira, Z. (1987). Managerial perspectives on risk and risk taking. Management Science, 33(11), 1404-1418.

McDonald, D. B. (2007). Predicting fate from early connectivity in a social network. Proceedings of the National Academy of Sciences, 104(26), 10910-10914.

McKinney, E. H., Jr., \& Yoos, C. J. (2010). Information about information: A taxonomy of views. MIS Quarterly, 34(2), 329-344.

Mendoza, M., Poblete, B., \& Castillo, C. (2010). Twitter under crisis: Can we trust what we RT? In Proceedings of the First Workshop on Social Media Analytics (pp. 71-79). ACM.

Metzger, M. J., Flanagin, A. J., \& Medders, R. B. (2010). Social and heuristic approaches to credibility evaluation online. Journal of Communication, 60(3), 413-439.

Miller, H. (1996). The multiple dimensions of information quality. Information Systems Management, 13(2), 79-82.

Mislove, A., Marcon, M., Gummadi, K. P., Druschel, P., \& Bhattacharjee, B. (2007). Measurement and analysis of online social networks. In Proceedings of the 7 th ACM SIGCOMM conference on Internet measurement (pp. 2942). ACM.

Naumann, F., \& Rolker, C. (2000). Assessment methods for information quality criteria. In Proceedings of the Fifth Conference on Information Quality (IQ 2000) (pp. 148-162).

Nicolaou, A. I., Ibrahim, M., \& Van Heck, E. (2013). Information quality, trust, and risk perceptions in electronic data exchanges. Decision Support Systems, 54(2), 986-996.

Nicolaou, A. I., \& McKnight, D. H. (2006). Perceived information quality in data exchanges: Effects on risk, trust, and intention to use. Information Systems Research, 17(4), 332-351.

Nunnally, J. C., Bernstein, I. H., \& Berge, J. M. F. (1967). Psychometric theory (Vol. 226). McGraw-Hill New York.

Oh, O., Agrawal, M., \& Rao, H. R. (2013). Community intelligence and social media services: A rumor theoretic analysis of tweets during social crises. MIS Quarterly, 37(2), 407-426.

Osatuyi, B. (2013). Information sharing on social media sites. Computers in Human Behavior, 29(6), 2622-2631.

Pelling, E. L., \& White, K. M. (2009). The theory of planned behavior applied to young people's use of social networking web sites. CyberPsychology \& Behavior, 12(6), 755-759.

Peng, G., Fan, M., \& Dey, D. (2011). Impact of network effects and diffusion channels on home computer adoption. Decision Support Systems, 51(3), 384-393.

Podsakoff, P. M., MacKenzie, S. B., Lee, J.-Y., \& Podsakoff, N. P. (2003). Common method biases in behavioral research: A critical review of the literature and recommended remedies. Journal of Applied Psychology, 88(5), 879.

Polansky, A., Heimann, G., Schiller, V., \& Morgan, L. (2017). A real plague: Fake news. Marketing Weekly News, 61. Retrieved from http://www.webershandwick.com/uploads/news/files/A Real Plague Fake News.pdf

Posey, C., Lowry, P. B., Roberts, T. L., \& Ellis, T. S. (2010). Proposing the online community self-disclosure model: The case of working professionals in France and the UK who use online communities. European Journal of Information Systems, 19(2), 181-195.

Pradhan, S., \& Gay, V. (2013). Towards a new trust model for health social networks. In The Eighth International Conference on Internet and Web Applications and Services (ICIW 2013) (pp. 52-57).

Price, R., Neiger, D., \& Shanks, G. (2008). Developing a measurement instrument for subjective aspects of information quality. Communications of the Association for Information Systems, 22(1), 3.

Schaal, M., Smyth, B., Mueller, R. M., \& MacLean, R. (2012). Information quality dimensions for the social web. In Proceedings of the International Conference on Management of Emergent Digital EcoSystems (pp. 53-58). ACM. 
Schoenbachler, D. D., \& Gordon, G. L. (2002). Trust and customer willingness to provide information in database-driven relationship marketing. Journal of Interactive Marketing, 16(3), 2-16. https://doi.org/10.1002/dir.10033

Shannon, C. E., \& Weaver, W. (1949). The mathematical theory of communication. The University of Illinois Press. Retrieved from http://www.ncbi.nlm.nih.gov/pubmed/9230594

Shi, N., Lee, M. K. O., Cheung, C., \& Chen, H. (2010). The continuance of online social networks: How to keep people using Facebook? 43rd Hawaii International Conference on System Sciences (HICSS). IEEE.

Shi, Z., Rui, H., \& Whinston, A. (2014). Content sharing in a social broadcasting environment: Evidence from twitter. Mis Quarterly, 38(1), 123-142. https://doi.org/10.2139/ssrn.2341243

Sitkin, S. B., \& Pablo, A. L. (1992). Reconceptualizing the determinants of risk behavior. Academy of Management Review, 17(1), 9-38.

Sitkin, S. B., \& Weingart, L. R. (1995). Determinants of risky decision-making behavior: A test of the mediating role of risk perceptions and propensity. Academy of Management Journal, 38(6), 1573-1592.

Stein, J. (2016, August 18). How trolls are ruining the internet. Time Magazine. Retrieved from http://time.com/4457110/internet-trolls/

Suh, B., Hong, L., Pirolli, P., \& Chi, E. H. (2010). Want to be retweeted? Large scale analytics on factors impacting retweet in twitter network. In PASSAT 2010: 2nd IEEE International Conference on Privacy, Security, Risk and Trust (pp. 177-184). https://doi.org/10.1109/SocialCom.2010.33

Sykes, T. A., Venkatesh, V., \& Gosain, S. (2009). Model of acceptance with peer support: A social network perspective to understand employees' system use. MIS Quarterly, 33(2), 9.

Taylor, S., \& Todd, P. A. (1995). Understanding information technology usage: A test of competing models. Information Systems Research, 6(2), 144-176.

Tschersich, M., \& Botha, R. A. (2013). Understanding the impact of default privacy settings on self-disclosure in social networking services: Building a conceptual model and measurement instrument. In Proceedings of the Nineteenth Americas Conference on Information Systems.

Utz, S. (2015). The function of self-disclosure on social network sites: Not only intimate, but also positive and entertaining self-disclosures increase the feeling of connection. Computers in Human Behavior, 45, 1-10.

Valente, T. W., Gallaher, P., \& Mouttapa, M. (2004). Using social networks to understand and prevent substance use: A transdisciplinary perspective. Substance Use \& Misuse, 39(10-12), 1685-1712.

Van der Heijden, H. (2003). Factors influencing the usage of websites: the case of a generic portal in The Netherlands. Information \& Management, 40(6), 541-549.

Venkatesh, V., Morris, M., Davis, G., \& Davis, F. (2003). User acceptance of information technology: Toward a unified view. MIS Quarterly, 27(3), 425-478. Retrieved from http://www.jstor.org/stable/30036540

Verplanken, B. (2006). Beyond frequency: Habit as mental construct. British Journal of Social Psychology, 45(3), 639-656.

Viswanath, B., Mislove, A., Cha, M., \& Gummadi, K. P. (2009). On the evolution of user interaction in facebook. In Proceedings of the 2nd ACM workshop on Online social networks (pp. 37-42). ACM.

Wagner, K. (2014). Facebook passes 1 billion monthly mobile users. Retrieved from http://mashable.com/2014/04/23/facebook-1-billion-mobile-users/

Wasko, M. M., \& Faraj, S. (2005). Why should I share? Examining social capital and knowledge contribution in electronic networks of practice. MIS Quarterly, 29(1), 35-57.

Wilson, T. D. (1981). On user studies and information needs. Journal of Documentation, 37(1), 3-15.

Wixom, B. H., \& Todd, P. A. (2005). A theoretical integration of user satisfaction and technology acceptance. Information Systems Research, 16(1), 85-102.

Xiang, Z., \& Gretzel, U. (2010). Role of social media in online travel information search. Tourism Management, 31(2), 179-188. 
Xie, W. (2014). Social network site use, mobile personal talk and social capital among teenagers. Computers in Human Behavior, 41, 228-235.

Xu, F., Michael, K., \& Chen, X. (2013). Factors affecting privacy disclosure on social network sites: An integrated model. Electronic Commerce Research, 13(2), 151-168.

Yang, Z., Cai, S., Zhou, Z., \& Zhou, N. (2005). Development and validation of an instrument to measure user perceived service quality of information presenting web portals. Information \& Management, 42(4), 575-589.

Zhao, S., Grasmuck, S., \& Martin, J. (2008). Identity construction on Facebook: Digital empowerment in anchored relationships. Computers in Human Behavior, 24(5), 1816-1836.

Zlatolas, L. N., Welzer, T., Heričko, M., \& Hölbl, M. (2015). Privacy antecedents for SNS self-disclosure: The case of Facebook. Computers in Human Behavior, 45, 158-167.

Zmud, R. W. (1978). An empirical investigation of the dimensionality of the concept of information. Decision Sciences, 9(2), 187-195.

\section{APPENDICES}

Appendix A. Breakdown of invalid and incomplete responses

\begin{tabular}{|l|c|}
\hline Reason of deletion & $\begin{array}{l}\text { Number of } \\
\text { deleted responses }\end{array}$ \\
\hline Incomplete responses & 40 \\
\hline Responses indicating that the respondent does not use any of SNSs & 27 \\
\hline $\begin{array}{l}\text { Responses with very short response time (an average response time of less } \\
\text { than } 3 \text { minutes deemed insufficient to adequately respond to survey ques- } \\
\text { tions) }\end{array}$ & 10 \\
\hline Total deleted & $\mathbf{7 7}$ \\
\hline
\end{tabular}


Appendix B. Measurement items and factor loadings

\begin{tabular}{|c|c|c|c|c|c|c|c|c|c|}
\hline No. & Measurement Item & Item & ATT & ENJ & INT & REL & RELI & RIS & References \\
\hline 1 & It is a good idea to use SNSs. & ATT1 & 0.87 & 0.49 & 0.54 & 0.37 & 0.30 & 0.21 & \multirow{5}{*}{$\begin{array}{l}\text { (Bhattacherjee \& } \\
\text { Premkumar, } \\
\text { 2004) }\end{array}$} \\
\hline 2 & Using a SNS is a wise move. & ATT2 & 0.90 & 0.54 & 0.54 & 0.46 & 0.37 & 0.30 & \\
\hline 3 & $\begin{array}{l}\text { I have an extremely positive } \\
\text { attitude toward using SNSs. }\end{array}$ & ATT3 & 0.89 & 0.61 & 0.52 & 0.50 & 0.46 & 0.23 & \\
\hline 4 & Using SNSs is a positive step. & ATT4 & 0.91 & 0.56 & 0.48 & 0.47 & 0.42 & 0.24 & \\
\hline 5 & $\begin{array}{l}\text { It is favorable for me to use } \\
\text { SNSs. }\end{array}$ & ATT5 & 0.86 & 0.57 & 0.56 & 0.46 & 0.36 & 0.25 & \\
\hline 6 & $\begin{array}{l}\text { The information includes } \\
\text { lots of fun. }\end{array}$ & ENJ1 & 0.60 & 0.88 & 0.52 & 0.49 & 0.41 & 0.29 & \multirow[t]{3}{*}{$\begin{array}{l}\text { (Schaal et al., } \\
\text { 2012) }\end{array}$} \\
\hline 7 & $\begin{array}{l}\text { The information is very en- } \\
\text { joyable. }\end{array}$ & ENJ2 & 0.57 & 0.91 & 0.49 & 0.48 & 0.39 & 0.33 & \\
\hline 8 & $\begin{array}{l}\text { The information I see is en- } \\
\text { tertaining. }\end{array}$ & ENJ3 & 0.47 & 0.83 & 0.37 & 0.51 & 0.40 & 0.20 & \\
\hline 9 & $\begin{array}{l}\text { I am willing to re-share im- } \\
\text { ages I see posted on SNSs }\end{array}$ & INT1 & 0.56 & 0.52 & 0.93 & 0.40 & 0.32 & 0.29 & \multirow{5}{*}{$\begin{array}{c}\text { (Koehorst, 2013; } \\
\text { Schoenbachler } \\
\text { \& Gordon, } \\
\text { 2002) }\end{array}$} \\
\hline 10 & $\begin{array}{l}\text { I am willing to re-share vide- } \\
\text { os I see posted on SNS. }\end{array}$ & INT2 & 0.54 & 0.50 & 0.91 & 0.38 & 0.33 & 0.27 & \\
\hline 11 & $\begin{array}{l}\text { I am willing to re-share news } \\
\text { I see posted on SNS. }\end{array}$ & INT3 & 0.49 & 0.45 & 0.89 & 0.30 & 0.25 & 0.28 & \\
\hline 12 & $\begin{array}{l}\text { I am willing to re-share in- } \\
\text { formation I see posted on } \\
\text { SNSs. }\end{array}$ & INT4 & 0.54 & 0.47 & 0.93 & 0.40 & 0.32 & 0.31 & \\
\hline 13 & $\begin{array}{l}\text { I am willing to re-share } \\
\text { events I see posted on SNSs. }\end{array}$ & INT5 & 0.56 & 0.47 & 0.87 & 0.42 & 0.35 & 0.25 & \\
\hline 14 & $\begin{array}{l}\text { This information is relevant } \\
\text { to my goals on SNS. }\end{array}$ & REL1 & 0.50 & 0.54 & 0.41 & 0.96 & 0.50 & 0.20 & \multirow{3}{*}{$\begin{array}{c}\text { (Y. Lee et al., } \\
\text { 2002; Nicolaou } \\
\text { \& McKnight, } \\
\text { 2006) }\end{array}$} \\
\hline 15 & $\begin{array}{l}\text { This information is appro- } \\
\text { priate for my goals on SNS. }\end{array}$ & REL2 & 0.49 & 0.55 & 0.40 & 0.97 & 0.53 & 0.16 & \\
\hline 16 & $\begin{array}{l}\text { This information is applica- } \\
\text { ble to my goal on SNS. }\end{array}$ & REL3 & 0.49 & 0.54 & 0.42 & 0.97 & 0.53 & 0.19 & \\
\hline 17 & $\begin{array}{l}\text { The information shared on } \\
\text { SNS is reliable. }\end{array}$ & RELI1 & 0.42 & 0.44 & 0.37 & 0.49 & 0.92 & 0.22 & \multirow{3}{*}{$\begin{array}{l}\text { (Y. Lee et al., } \\
\text { 2002; Price, } \\
\text { Neiger, \& } \\
\text { Shanks, 2008) }\end{array}$} \\
\hline 18 & $\begin{array}{l}\text { The information shared on } \\
\text { SNS is dependable. }\end{array}$ & RELI3 & 0.39 & 0.42 & 0.30 & 0.47 & 0.93 & 0.18 & \\
\hline 19 & $\begin{array}{l}\text { The information shared on } \\
\text { SNS can be relied upon. }\end{array}$ & RELI3 & 0.38 & 0.40 & 0.28 & 0.53 & 0.92 & 0.19 & \\
\hline 20 & $\begin{array}{l}\text { I have a propensity to take } \\
\text { associated risks. }\end{array}$ & RIP1 & 0.21 & 0.28 & 0.21 & 0.15 & 0.16 & 0.79 & \multirow[t]{3}{*}{$\begin{array}{l}\text { (Chen et al., } \\
\text { 2011) }\end{array}$} \\
\hline 21 & $\begin{array}{l}\text { I have a positive view of } \\
\text { risk-taking decisions. }\end{array}$ & RIP2 & 0.25 & 0.28 & 0.26 & 0.17 & 0.20 & 0.90 & \\
\hline 22 & $\begin{array}{l}\text { I feel it is necessary to take } \\
\text { risks for successful results. }\end{array}$ & RIP3 & 0.25 & 0.26 & 0.30 & 0.17 & 0.19 & 0.87 & \\
\hline
\end{tabular}




\section{BIOGRAPHIES}

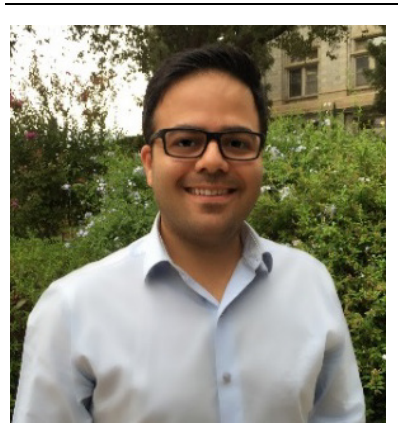

Dr. Mehrdad Koohikamali is an Assistant Professor of Business GIS at the University of Redlands. Mehrdad received his Ph.D. in Information Systems at University of North Texas. He holds an M.S. in Applied GIS from the University of North Texas and an M.S. in GIS from the University of Tehran. His research and professional interests include location intelligence for business, big data analytics, social media analytics, and information privacy. His work appears in such journals as Decision Support System, Computers in Human Behavior, and Lecture Notes in Business Information Processing. He has won several awards such as IT innovation for teaching, faculty research grant, and best doctoral paper.

Mehrdad has several years of working experience in the field of GIS, ranging from GIS consultant, analyst, and a programmer to GIS manager.

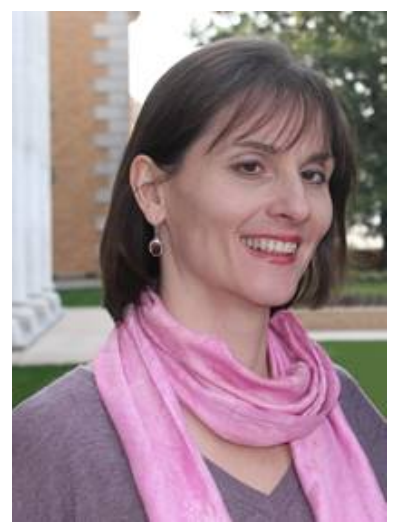

Dr. Anna Sidorova is an Associate Professor of information systems in the Information Technology and Decision Sciences Department at the University of North Texas. Her research and professional interests include business applications of AI and machine learning, business intelligence and analytics, business process management, and IS discipline development. Her work appears in such journals as MIS Quarterly, Journal of Management Information Systems, Journal of the Association for Information Systems, Information and Management, and Decision Support Systems. She teaches a variety of course including analysis of business information systems, information systems development, and foundations of database management systems. She received her doctorate from the Washington State University. 